\title{
¿ECONOMÍA DOMÉSTICA O LABORES? LA EDUCACIÓN FEMENINA EN LA ESCUELA: PROGRAMAS Y LIBROS DE TEXTO (ARGENTINA, 1870-1920)
}

\author{
Domestic Economy in the school. Women's education: \\ programs and textbooks (Argentina, 1870-1920)
}

\section{Laura Graciela Rodríguez ${ }^{\bigotimes}$}

Fecha de recepción: 26/11/2020 • Fecha de aceptación: 23/03/2021

Resumen. En Argentina, a partir del año 1870 se comenzaron a crear, a instancias de Domingo F. Sarmiento, las primeras Escuelas Normales nacionales. Al igual que en otros países, la expansión de las Normales ha respondido a la necesidad de formar maestros y maestras que se ocupasen de alfabetizar a la mayoría de la población, moralizar a los sectores populares, transmitirles los principios básicos del higienismo y hacerlos parte de una misma comunidad nacional. En estos nacientes Estados modernos, las máximas autoridades decidieron brindar una educación diferenciada a las niñas, para que aprendiesen a ser buenas amas de casa, esposas, y madres, a través de la transmisión de contenidos preparados especialmente para ellas. Imitando a países como Estados Unidos, Francia o Bélgica, se incluyeron, tanto en los cursos de magisterio como en las escuelas primarias, las asignaturas de Labores de mano y Economía Doméstica. En este artículo analizaremos: a) de qué manera se ubicaron estas dos materias en los planes de estudio elaborados para las escuelas primarias de la provincia de Buenos Aires, de la ciudad de Buenos Aires y el curso de magisterio, qué carga horaria le destinaron y cómo fueron evolucionando; b) qué contenidos y propósitos perseguían los programas de ambas asignaturas; c) qué temas se trataban en los textos seleccionados por las autoridades oficiales; d) y cómo era su enseñanza en el aula.

Palabras claves: Escuela Normal; mujeres; economía doméstica; labores; educación de las emociones.

\footnotetext{
a IdIHCS. Instituto de Investigaciones en Humanidades y Ciencias Sociales, Universidad Nacional de La Plata - CONICET. Calle 51 e/124 y 125. Ensenada, Provincia de Buenos Aires, Argentina. lau.g.rodrig@gmail.com (1D https://orcid.org/0000-0001-9757-5609
}

Cómo citar este artículo: Rodríguez, Laura Graciela. «¿Economía Doméstica o Labores? La educación femenina en la escuela: programas y libros de texto (Argentina, 1870- 1920)». Historia y Memoria de la Educación 14 (2021): 615-641 
Abstract. In Argentina, starting in the year 1870 the first national Normal Schools (Teacher Training Schools) were created at the initiative of Domingo F. Sarmiento. As in other countries, the expansion of Normal Schools responded to the need to train teachers in order to give instruction to the majority of the population, to provide moral guidance to popular sectors, to transmit basic principles of hygiene, and to help make them part of the same national community. In these nascent modern states, functionaries also had to take care of providing a differentiated education to girls, so that they would learn to be good wives, mothers and housewives, through the transmission of content prepared especially for them. Imitating countries such as the United States, France or Belgium, the subject Domestic Economy was included in Normal Schools and primary schools. In this article we will discuss: a) how the subject was incorporated into the curriculum developed for the primary schools of the province of Buenos Aires as well as the capital city, what the course loads consisted of, and how they evolved; $b$ ) what content and purposes the programs pursued; c) what topics were dealt with in the texts selected by the official authorities; d) and how the subject was taught in the classroom.

Keywords: Normal Schools; women; domestic economy; education of emotions.

«Elena es una niña muy buenita y muy querida:

lava, cocina, plancha, cose, barre, estudia

y todo lo hace con gusto y alegría».

Libro de lectura para primer grado

(usado por la autora)

Constancio Vigil, Upa!, (Buenos Aires: Atlántida, 1977), 83-84.

\section{INTRODUCCIÓN}

En Argentina, a partir del año 1870 se comenzaron a crear, a instancias de Domingo F. Sarmiento, las primeras Escuelas Normales nacionales. Al igual que en otros países, la expansión de las Normales ha respondido a la necesidad de formar maestros y maestras que se ocupasen de alfabetizar a la mayoría de la población, moralizar a los sectores populares, transmitirles los principios básicos del higienismo y hacerlos parte de una misma comunidad nacional. En estos nacientes Estados modernos, los máximos funcionarios se ocuparon, además, de brindar una educación diferenciada a las niñas, para que aprendiesen a ser buenas amas de casa, esposas y madres, a través de la transmisión de contenidos 
especialmente preparados para ellas. Imitando a países como Estados Unidos, Francia o Bélgica, se incluyeron, tanto en los cursos de magisterio como en las escuelas primarias, las asignaturas de Labores de mano y Economía Doméstica.

Existen investigaciones que han estudiado el contenido de algunos de estos manuales de Economía Doméstica, poniendo el énfasis en cómo buscaron introducir a las mujeres en el conocimiento de las tareas del hogar. ${ }^{1}$ Ha sido menos visto de qué manera estas materias se inscribieron en el currículum oficial desde que la escuela primaria se hizo obligatoria, y cuáles fueron los textos autorizados por los funcionarios para ser utilizados en las escuelas y Normales. En base a estas investigaciones precedentes, en este artículo analizaremos: a) de qué manera se ubicaron estas dos materias -Labores y Economía Doméstica- en los planes de estudio elaborados para las escuelas primarias de la provincia de Buenos Aires, de la ciudad de Buenos Aires y el curso de magisterio, qué carga horaria le destinaron y cómo fueron evolucionando; b) qué contenidos y propósitos perseguían los programas de ambas asignaturas; c) qué temas se trataban en los textos seleccionados por las autoridades oficiales; d) y cómo era su enseñanza en el aula. Intentaremos mostrar, en primer término, que ambas materias se fueron ubicando de maneras distintas en los planes de estudio de las primarias de provincia, de ciudad y en las Normales, aunque siempre destinando a las niñas una menor carga horaria de otras asignaturas, para que pudiesen cursarlas. En segundo término, observaremos que cada una de estas materias en la primaria, tenía contenidos y fines diferentes, y estaban destinadas a niñas de distintos sectores sociales. En tercer lugar, mostraremos en qué

\footnotetext{
1 Marcela Nari, «La educación de la mujer (O acerca de cómo cocinar y cambiar pañales a su bebé de manera científica)», Revista Mora, n. ${ }^{0} 1$ (1995): 31-45; Jorge F. Liernur, «El nido de la tempestad. La formación de la casa moderna en la Argentina a través de manuales y artículos sobre economía doméstica (1870-1910)», Entrepasados, n. ${ }^{\circ} 13$ (1997): 7-36; Paula Caldo. «Una disciplina con urbanidad: la Economía Doméstica. Aproximaciones a la problemática desde El Monitor de la Educación Común», en dir. Carolina Kaufmann Ahorran, acunan y martillan. Marcas de urbanidad en los escenarios educativos argentinos (primera mitad del siglo XX) (Paraná: UNER, 2012), 175-206; Adrián Cammarota «Los consejos de Amalia a su hija Laura. Propaganda moral y construcciones genéricas en un texto escolar a comienzos del siglo XX en Argentina», De prácticas y discursos, no 1, (2012): 1-20; Norma Alloatti «Desde la retórica doméstica a la inclusión de las hermanas de las letras en manuales escolares de fin de siglo XIX y comienzos del XX, ponencia presentada en XIII Jornadas Nacionales y VIII Congreso Iberoamericano de estudios de género: horizontes revolucionarios, voces y cuerpos en conflicto, http://eventosacademicos.filo.uba.ar/index.php/JNHM/XIII-VIII-2017/paper/ view/3585/2173 (consultado el 10-12- 2020); Paula Aguilar, El hogar como problema y solución (Buenos Aires: Centro Cultural de la Cooperación, 2018).
} 
sentido los textos de estas asignaturas se ocupaban, tanto de formar a las futuras amas de casa, de adiestrarlas en la contabilidad doméstica y la enseñanza práctica de los quehaceres del hogar, como de adquirir comportamientos adecuados y dominar las emociones negativas. Por último, respecto a cómo se impartían estas dos asignaturas en la primaria, contamos con algunos testimonios que nos hablan de cierta correspondencia entre los programas de Labores y su implementación en las clases; y un desajuste entre los contenidos de Economía Doméstica y lo que se daba efectivamente en el aula. A continuación, presentaremos estos argumentos en cuatro apartados, en el primero y segundo analizaremos los planes de estudio y programas de la provincia de Buenos Aires, de la ciudad de Buenos Aires y del curso de magisterio, en el tercero los libros de texto y al final, nos ocuparemos de la enseñanza de estas dos asignaturas.

\section{LOS PLANES DE ESTUDIO Y PROGRAMAS EN LA PROVINCIA DE BUENOS AIRES}

En 1875 se sancionó en la provincia de Buenos Aires la Ley de Educación Común, que estableció por primera vez la escolarización obligatoria en seis años, y en 1876, las escuelas de niñas que estaban bajo la supervisión de la Sociedad de Beneficencia - una organización de mujeres de la élite- pasaron a la órbita estatal. ${ }^{2}$ Ese año se aprobó el Reglamento general para las escuelas comunes de la provincia de Buenos Aires. Respecto a las materias, se disponía que en primer, segundo y tercer grado, las niñas tuviesen Labores y de cuarto a sexto, Labores y Economía Doméstica (cuadro 1). Como no había una carga horaria equivalente para los varones, a las niñas se les restaban minutos de las demás asignaturas: las alumnas de primero y segundo grado tenían dos horas menos de Lenguaje; en tercero y cuarto grado tenían una hora menos de Aritmética, media hora menos de Lecciones sobre objetos (Ciencias

\footnotetext{
2 Las primeras escuelas de niñas se crearon en Buenos Aires en 1823, estaban supervisadas por la Sociedad de Beneficencia y subvencionadas por el Estado, y tenían las «materias propias de su sexo» como costura y bordado, donde se utilizaban libros como el Manual para las escuelas elementales de niñas o resumen de enseñanza mutua, aplicada a la lectura, escritura, cálculo y costura de Madame Quignon, editado por la Imprenta de Niños Expósitos. En la enseñanza privada ocurría lo propio, por ejemplo, en 1839 Domingo F. Sarmiento fundó una escuela particular para mujeres en la provincia de San Juan -el Colegio Santa Rosa, que alcanzó a funcionar por un brevísimo tiempo-, que tenía Labores, Economía Doméstica, Dibujo Floral y Baile.
} 
Naturales), media hora menos de Dibujo lineal y una menos de Geometría; en quinto una hora menos de Aritmética; y en sexto, ellas no tenían Álgebra.

En relación con los contenidos de cada una, en los seis años de Labores se debía aprender costura a mano, punto de dobladillo, punto atrás, pespunte, punto guante, de marcar, de igualar, mallas de medias, tejido a crochet, dobladillo con vainilla, tejido con lana, corte de ropa blanca, bordado de letras, nombres, cortado de moldes para batones, zurcido de medias y remiendos. Acerca de Economía Doméstica, como veremos, los funcionarios fueron modificando los contenidos de esta asignatura en los distintos programas, incluyendo cuestiones de contabilidad doméstica, instrucciones para realizar las tareas del hogar y de educación de las emociones y comportamientos. Según uno de los autores de los manuales, ésta se impartía en las escuelas para enseñarles a las niñas y jóvenes «la manera de administrar recta y prudentemente los fondos destinados a satisfacer las necesidades diarias de una familia». ${ }^{3}$ En este primer programa de 1876, en Economía Doméstica de cuarto grado se daban: ejemplos del modo de cómo proveía el hombre a sus necesidades de alimento, vestido, descanso; y distinción entre las necesidades y comodidades de la vida. En quinto: los principios para hacer lucrativa la administración doméstica; limitación racional de los gastos diarios en consonancia con las rentas; distribución proporcional y sistemática del tiempo entre trabajo y descanso; y reglamentación del servicio doméstico. En sexto los contenidos eran: condiciones higiénicas de las habitaciones; conservación de alimentos, muebles y vestidos; remedios domésticos en caso de accidentes; necesidad y modo de llevar libros para asentar los acontecimientos importantes y económicos. ${ }^{4}$

En la revista oficial de la provincia, entre 1883 y 1884, se fueron publicando las primeras notas sobre estas dos materias «femeninas», escritas por Amelia Palma, quien luego redactaría uno de los textos para la primaria [ver más adelante]. En su primera intervención, aseguraba que las maestras debían familiarizar a las niñas hasta con los más insignificantes

\footnotetext{
3 Cipriano Torrejón y Lucía Aïn de Torrejón. Lecciones de Economía Doméstica (Buenos Aires: Casa editorial, 1887): 6.

4 Dirección General de Escuelas, «Reglamento para las escuelas comunes de la provincia de Buenos Aires», Anales de la Educación Común, n. ${ }^{\circ} 7$ (1876).
} 
detalles de una casa, siendo la cuestión más importante que aprendiesen a manejar el presupuesto. En otras notas hablaba de cómo preparar alimentos y bebidas. ${ }^{5}$ En 1884 se publicaron las Conferencias Pedagógicas para los/as maestros/as, y en una de ellas, una directora aseguraba que Labores bien enseñada, podría convertirse en una fuente de trabajo decente y lucrativo para las niñas. ${ }^{6}$

En 1890 se produjo una reforma a los programas. ${ }^{7}$ Se prescribía Labores desde primero a sexto, pero se reducía solo al cuarto grado Economía Doméstica (cuadro 1). Como sucedía antes con el horario, en las escuelas de niñas, ellas recibían menos minutos de clase de Escritura, Ejercicios intuitivos, Idioma nacional, Urbanidad, Gimnasia, Canto, Aritmética, Geografía, Historia, Instrucción cívica, Zoología, Física, Gramática, Dibujo, Química y Mineralogía. Los contenidos de Labores eran similares a los programas anteriores, y se les agregaban la confección de ropa blanca de niños, de cama y de mesa, ropa interior de hombre y mujer, corpiños, ojales, costuras de cordones y tejidos, vestidos de niños y bordados en lencería, tejido ñandutí, pasamanería, adornos para tapados, flecos y blondas, labores de fantasía y confección de flores artificiales. En Economía Doméstica de cuarto el programa giraba alrededor de la limitación racional de los gastos en consonancia con los ingresos; despensa: ahorros convenientes; cocina; quehaceres domésticos; reglamentación del servicio; distribución del tiempo; hábitos de orden y sistema; limpieza de las habitaciones; aparatos para el lavado y planchado de la ropa.

En 1899 el responsable de la cartera educativa advertía que los grados superiores de la escuela primaria (cuarto, quinto y sexto) casi no tenían alumnos/as y por ello resultaban muy costosos para los dineros públicos, al tiempo que presentaba una nueva modificación a los programas, que seguían teniendo Labores de primero a sexto, pero Economía Doméstica se pasaba a quinto grado (cuadro 1). ${ }^{8}$ En esta ocasión, mientras ellas cursaban Labores, los niños hacían Ejercicios de materias que

\footnotetext{
5 Amelia Palma, «Párrafos sobre Economía doméstica», Revista de Educación, n. ${ }^{19}$ (1883): 6- 11.

6 Flora de Mármol, «Enseñanza de Labores», Revista de Educación, n. ${ }^{\circ} 36$ (1884): 608-609.

7 Revista de Educación. Periódico oficial del CGE de la provincia de Buenos Aires, n. ${ }^{\circ} 112$ (1890).

8 Boletín de enseñanza y de administración escolar, n. ${ }^{\circ} 6$ (1899).
} 
en otros horarios cursaban juntos: Escritura, Aritmética e Idioma nacional. El programa de Labores era muy similar al anterior, al que se le agregó el uso de la máquina de coser en quinto y sexto grado. Esta nueva disposición suponía que había máquinas en las escuelas, pero por razones presupuestarias no todas las tuvieron y se siguió enseñando Labores de mano. En Economía Doméstica se habían agregado más contenidos, en sintonía con los nuevos libros que circulaban: la organización moral del hogar, condiciones del ama de casa, relaciones sociales de la familia, visitas y reuniones; la caridad, visitas a pobres y enfermos; la vida intelectual en el hogar, lecturas convenientes, biblioteca recomendable; la unión doméstica, la autoridad paterna; organización material y administración económica de la casa; empleo del tiempo de una ama de casa, cocina, lavado y planchado, calefacción y alumbrado; el jardín; contabilidad doméstica y ventajas del ahorro.

En 1904 las autoridades bonaerenses decidieron, por razones de ajuste presupuestario, reducir la obligatoriedad de la escuela primaria a los tres primeros grados, porque el Estado, decían, debía ocuparse de los/as niños/as más humildes que se iniciaban tempranamente en el trabajo. Los cursos de cuarto a sexto grado, según los funcionarios, eran mucho menos concurridos e iban solo los/as hijos/as de las familias más acomodadas. ${ }^{9}$ Se eliminaron varias asignaturas, entre ellas Economía Doméstica, dejando Labores desde primer grado (cuadro 1). En 1905 se modificó la Ley de Educación Común, se dejó la obligatoriedad en los primeros cuatro grados, se dispuso el ingreso a los ocho años y en 1906 se presentaron los nuevos programas con casi las mismas materias. ${ }^{10}$ En los fundamentos, los funcionarios aclaraban que el objetivo de la enseñanza de

\footnotetext{
9 En esos años, y a pesar de los esfuerzos estatales, seguía habiendo una porción importante de niñas pobres que no accedía a la escuela o solo lo hacía durante los primeros grados porque debía trabajar. En general, se empleaban a domicilio como costureras, modistas, cocineras, planchadoras y lavanderas y/o en talleres familiares pequeños. El segundo censo nacional de 1895 revelaba que, en la ciudad de Buenos Aires, un veinte por ciento de la fuerza de trabajo industrial estaba compuesto por mujeres que trabajaban en la confección de ropa interior, lencería, medias, ropa, sombreros y en las fábricas de textiles y tabaco. Ver, entre otros, Fernando Rocchi, «Concentración de capital, concentración de mujeres. Industria y trabajo femenino en Buenos Aires, 1890-1930», en Historia de las mujeres en la Argentina. Siglo XX, dirs. Fernanda Gil Lozano, Valeria Pita S y María G. Ini (Buenos Aires: Taurus, 2000), 223-244; Diego Armus. La ciudad impura (Buenos Aires: Edhasa, 2007); Mirta Lobato. Historia de las trabajadoras en la Argentina (1869-1960) (Buenos Aires: Edhasa, 2007). A partir de esta realidad, desde el año 1900 se comenzaron a crear Escuelas Profesionales femeninas, para que estas niñas y jóvenes pudiesen aprender alguno de estos oficios.
}

10 Revista de educación, n. ${ }^{\circ}$ 1-2 (1906). 
Labores era «familiarizar a las niñas en la práctica de los quehaceres domésticos», enseñando solo «lo útil y lo práctico» y desterrando «las labores de adorno». Los programas eran muy similares a los de otros años y como en los anteriores, en esas horas los varones hacían Ejercicios de las otras materias. Ante esta ausencia de Economía Doméstica en los programas oficiales, Amelia Palma escribió un artículo en la revista oficial donde remarcaba que dicha asignatura era «una de las ciencias de más utilidad a la familia humana y a la ciencia del bien vivir» y se preguntaba por qué el estudio del «manejo de la casa», una cuestión realmente trascendental, era mirado «tan por encima». ${ }^{11}$

En 1914 se presentó una nueva reforma al plan de estudios, que dejaba casi las mismas asignaturas, la obligatoriedad en cuatro años, y ubicaba Labores a partir del segundo grado hasta sexto (Cuadro 1). En los fundamentos se decía que el propósito de esa asignatura era que las niñas adquiriesen «la aptitud necesaria para bastarse a sí mismas, de tal modo que al término del ciclo escolar estén en condiciones de prepararse su ropa, siendo buenas amas de casa».12 Retomando los conceptos del anterior plan, se afirmaba que debía enseñarse lo útil y lo práctico, desecharse el lujo y desterrar los trabajos en seda y oro. Dos años después se volvió a ubicar Labores en el primer grado. Las autoridades justificaron la medida porque había niñas que abandonaban la escuela ya en segundo grado, mientras que en ese horario, igual que siempre, los varones hacían Ejercicios de las otras materias. Se aclaraba que la enseñanza de esta asignatura era «tanto para la mujer rica como la pobre» ya que ambas necesitaban «adquirir un conocimiento práctico de la costura y arte de hacer vestidos» para «ser capaz de hacerlos o juzgar el trabajo que su modista» le presentara. Asimismo, «componer la ropa, zurcirla y remendarla», proporcionaba en los hogares modestos «una economía tan notoria» que ese conocimiento constituía un «verdadero tesoro para el hogar». La escuela estaba «formando a las futuras madres», las que en su gran mayoría vivirán «del trabajo honrado del esposo», por lo que tendrán que ingeniarse "para gastar lo menos posible».13 Se ordenaba a la maestra que tuviesen «su muestrario propio de todos

\footnotetext{
11 Amelia Palma, «Párrafos de Economía Doméstica», Revista de Educación, n. ${ }^{\circ} 3$ (1912): 585.

12 Revista de Educación, s/n (1914): 274.

13 Revista de Educación, n. 3 (1916): 354.
} 
los temas de enseñanza, sus moldes de papel para las piezas de costura y sus modelos para las prendas tejidas».

Cuadro 1. Labores y Economía Doméstica en escuelas primarias de la provincia de Buenos Aires

\begin{tabular}{|c|c|c|c|c|c|c|}
\hline $\begin{array}{l}\text { Planes de } \\
\text { estudio }\end{array}$ & 1. er grado & $2 .^{\circ}$ grado & 3..$^{\text {er }}$ grado & $4 .^{\circ}$ grado & $5 .^{\circ}$ grado & $6 .^{\circ}$ grado \\
\hline 1876 & Labores & Labores & Labores & $\begin{array}{l}\text { Labores y } \\
\text { Economía } \\
\text { Doméstica }\end{array}$ & $\begin{array}{l}\text { Labores y } \\
\text { Economía } \\
\text { Doméstica }\end{array}$ & $\begin{array}{l}\text { Labores y } \\
\text { Economía } \\
\text { Doméstica }\end{array}$ \\
\hline 1890 & Labores & Labores & Labores & $\begin{array}{l}\text { Labores y } \\
\text { Economía } \\
\text { Doméstica }\end{array}$ & Labores & Labores \\
\hline 1899 & Labores & Labores & Labores & Labores & $\begin{array}{l}\text { Labores y } \\
\text { Economía } \\
\text { Doméstica }\end{array}$ & Labores \\
\hline $\begin{array}{l}1903 \\
\text { (obligatoriedad } \\
\text { hasta tercer } \\
\text { grado) }\end{array}$ & Labores & Labores & Labores & Labores & Labores & Labores \\
\hline $\begin{array}{l}1905 \\
\text { (obligatoriedad } \\
\text { hasta cuarto } \\
\text { grado) }\end{array}$ & Labores & Labores & Labores & Labores & Labores & Labores \\
\hline 1914 (ígual) & - & Labores & Labores & Labores & Labores & Labores \\
\hline 1916 (ígual) & Labores & Labores & Labores & Labores & Labores & Labores \\
\hline
\end{tabular}

Fuente: elaboración propia en base a los planes y programas oficiales.

\section{LOS PLANES DE ESTUDIO DE LAS ESCUELAS PRIMARIAS DE LA CIUDAD DE BUENOS AIRES Y DEL CURSO DE MAGISTERIO DE LAS NORMALES}

En 1880 la provincia de Buenos Aires cedió a la nación la ciudad de Buenos Aires para que se transformara en la Capital Federal de la República. La nación debió entonces sancionar una nueva Ley de Educación, que fue la 1420 aprobada en 1884, que regía para las escuelas primarias de Capital Federal, los Territorios Nacionales y posteriormente, para las primarias nacionales ubicadas en las provincias. En la Ley se prescribió 
un mínimo de materias y la única distinción por sexo que se hizo fue la de Labores de mano y Economía Doméstica para las niñas y Ejercicios y Evoluciones militares para ellos. Sin embargo, como ocurría en provincia de Buenos Aires, al no prescribirse una carga horaria para cada materia, los programas de 1884 y 1887 para las escuelas de Capital, disponían que las niñas de primero a sexto grado tuviesen menos minutos de Aritmética, Ejercicios intuitivos, Moral y Urbanidad, Geometría, Francés e Instrucción Cívica. Tenían Labores de primero a tercer grado, en cuarto cursaban Economía Doméstica; y en quinto y sexto Labores, corte y confección (cuadro 2). Los contenidos de Labores y Economía Doméstica eran similares a los que se daban en provincia para esa época.

En 1895, el inspector Pablo Pizzurno impulsó una reforma en los programas, que comenzaron a estar vigentes en 1896, donde se introdujo la novedad del Trabajo Manual con la misma carga horaria para ambos sexos pero con contenidos distintos, y se extendió Economía Doméstica solo para niñas de primero a sexto. Por estar cursando esa asignatura, ellas tenían menos tiempo de Geometría, Aritmética, Dibujo, Ciencias Físico-Naturales, Instrucción Moral y Cívica e Higiene. En relación con los programas, el de Trabajo Manual para los varones debía hacer eje en la elaboración de piezas en madera, pero no todas las escuelas tuvieron las herramientas necesarias. Para las niñas, el Trabajo Manual seguía el anterior programa de Labores con más énfasis en la elaboración de distintas prendas (fundas, toallas, delantales, camisas, mangas, tejidos de lana, ropa interior, vestidos, batas, toda clase de ropa en sexto). A esto se le sumaban actividades propias de lo que se entendía por Trabajo Manual: el trenzado, tejido, picado, corte, calado y plegado; forrado de libros y cuadernos; esculturas en papel, confección de objetos útiles en cartón, compostura de libros; confección de sólidos geométricos en cartulina y de objetos útiles en cartón; modelado y combinación de formas geométricas y naturales. El programa de Economía Doméstica estaba dividido en "Gobierno del hogar» y «Ocupaciones domésticas». Entre los contenidos más importantes estaban, para primer grado: conversaciones sobre la habitación, gastos de la casa, cuidado de animales domésticos y plantas; segundo grado: diversas clases de alimentos; tercer grado: condiciones requeridas para la salubridad de una casa, la moda y el lujo en los vestidos, primeros auxilios; en cuarto: tarea de cada 
día, la economía y el ahorro, las deudas, pastelería y repostería; en quinto: gobierno de los criados, presupuesto, anotación de los gastos, lecturas de libros y periódicos en el hogar; y en sexto: contabilidad doméstica y la educación de los hijos. ${ }^{14}$

En 1901 se presentó por primera vez un plan, también de Pizzurno, con programas que tenían la misma carga horaria para todas las materias sin distinción de sexo. Varones y mujeres hacían Trabajo Manual y bajo ese nuevo rótulo, ellas seguían estos últimos programas de Labores y Economía Doméstica. En 1907 se hizo un ajuste y se dejó Economía Doméstica solo para los quinto y sexto grados, con un programa extremadamente resumido, donde debían darse solamente trabajos prácticos de limpieza; lavado, planchado y cocina (cuadro 2).

En las Escuelas Normales nacionales, los planes de estudio del curso de magisterio de 1876, 1880, 1886 y 1887 destinados a la formación de maestras, igual que en la primaria, tuvieron para las mujeres menos minutos o fueron suprimidas, distintas asignaturas: Aritmética, Gramática, Álgebra, Fisiología, Teneduría de libros, Geometría, Física, Trigonometría, Química, Cálculo, Cosmografía, Topografía, Agrimensura, Constitución de la República Argentina y principios de gobierno e Inglés. ${ }^{15}$ En ese tiempo, ellas debían cursar Labores, Higiene Doméstica y Economía Doméstica (cuadro 3). Lo mismo sucedió con los programas para las primarias normales, donde se había sumado Trabajo Manual. Casi al mismo tiempo que en las primarias de Capital, los contenidos en las Normales se igualaron por primera vez a partir de 1903, y mientras ellas hacían Economía Doméstica, ellos cursaban Agricultura y Ganadería y en los cursos siguientes, ellos seguían con Trabajo Manual (que también tenían ellas). Este plan de 1903 casi no se pudo aplicar porque se lo reemplazó por otro en 1905 que tenía Labores y Economía Doméstica los cuatro años, mientras los varones hacían materias prácticas. En 1914 se dio a conocer un nuevo plan que dejó Economía Doméstica solo para cuarto año.

\footnotetext{
14 Ministerio de Instrucción Pública, Educación Común en la Capital, provincias y Territorios Nacionales. Año 1897-1898 (Buenos Aires: Compañía Sud Americana).

15 Rodríguez, Laura Graciela. «Maestros y maestras y la cuestión de género: planes de estudio, salarios y feminización (Argentina, 1870-1914)». Descentrada. Revista interdisciplinaria de feminismos y género, n. ${ }^{\circ} 1$ (2021): 1-17.
} 
Cuadro 2. Labores y Economía Doméstica en las escuelas primarias de la ciudad de Buenos Aires

\begin{tabular}{|c|c|c|c|c|c|c|}
\hline $\begin{array}{l}\text { Planes } \\
\text { de } \\
\text { estudio }\end{array}$ & 1. ${ }^{\text {er }}$ grado & $2 .^{\circ}$ grado & 3..$^{\text {er }}$ grado & $4 .^{\circ}$ grado & $5 .^{\circ}$ grado & $6 .^{\circ}$ grado \\
\hline $\begin{array}{l}1884 \text { y } \\
1887\end{array}$ & Labores & Labores & Labores & $\begin{array}{l}\text { Labores y } \\
\text { Economía } \\
\text { Doméstica }\end{array}$ & $\begin{array}{l}\text { Labores, } \\
\text { corte y } \\
\text { confección }\end{array}$ & $\begin{array}{l}\text { Labores, } \\
\text { corte y } \\
\text { confección }\end{array}$ \\
\hline 1896 & $\begin{array}{l}\text { Economía } \\
\text { Doméstica (m) } \\
\text { y Trabajo } \\
\text { Manual } \\
\text { (ambos sexos, } \\
\text { Labores para } \\
\text { mujeres) }\end{array}$ & Igual & Igual & Igual & Igual & Igual \\
\hline 1901 & $\begin{array}{l}\text { Trabajo } \\
\text { Manual } \\
\text { (ambos sexos, } \\
\text { Economía } \\
\text { Doméstica y } \\
\text { Labores para } \\
\text { mujeres) }\end{array}$ & Igual & Igual & Igual & Igual & Igual \\
\hline 1907 & $\begin{array}{l}\text { Trabajo } \\
\text { Manual } \\
\text { (ambos sexos, } \\
\text { Labores para } \\
\text { mujeres) }\end{array}$ & $\begin{array}{l}\text { Trabajo } \\
\text { Manual } \\
\text { (ambos } \\
\text { sexos, } \\
\text { Labores } \\
\text { para } \\
\text { mujeres) }\end{array}$ & $\begin{array}{l}\text { Trabajo } \\
\text { Manual } \\
\text { (ambos } \\
\text { sexos, } \\
\text { Labores } \\
\text { para } \\
\text { mujeres) }\end{array}$ & $\begin{array}{l}\text { Trabajo } \\
\text { Manual } \\
\text { (ambos } \\
\text { sexos, } \\
\text { Labores } \\
\text { para } \\
\text { mujeres) }\end{array}$ & $\begin{array}{l}\text { Trabajo } \\
\text { Manual } \\
\text { (ambos } \\
\text { sexos, } \\
\text { Economía } \\
\text { Doméstica } \\
\text { y Labores } \\
\text { para } \\
\text { mujeres) }\end{array}$ & $\begin{array}{l}\text { Trabajo } \\
\text { Manual } \\
\text { (ambos } \\
\text { sexos, } \\
\text { Economía } \\
\text { Doméstica } \\
\text { y Labores } \\
\text { para } \\
\text { mujeres) }\end{array}$ \\
\hline
\end{tabular}

Fuente: elaboración propia en base a los planes y programas oficiales.

Por otra parte, las autoridades preferían, para dar Economía Doméstica y Labores en la primaria, a las maestras formadas en las Normales, pero si la escuela tenía presupuesto para una docente específica, estas solían ser egresadas de la Escuela Profesional de Mujeres N. ${ }^{\circ} 1$ de la Capital fundada en 1900, o del Instituto de Economía Doméstica, un establecimiento privado católico -el San Vicente de Paul- que estaba adscripto desde 1916 a la Escuela Normal N. ${ }^{\circ} 6$ de mujeres de Capital. En 1926 el ministro fundó el primer Profesorado de Economía Doméstica 
de carácter público, en la misma Normal N. ${ }^{\circ}$ 6. Su plan tenía dos años y las siguientes asignaturas: Física y Química aplicada; Fisiología e Higiene; Puericultura; Primeros Auxilios y cuidado de los enfermos; Higiene de la alimentación y cocina; Corte y confección; Dibujo aplicado; Trabajo Manual; Zurcido, planchado, lavado, remiendos, etc.; y Práctica de la enseñanza.

Cuadro 3. Labores y Economía Doméstica en el curso de magisterio de las Escuelas Normales nacionales

\begin{tabular}{|l|l|l|l|l|}
\hline $\begin{array}{l}\text { Planes de } \\
\text { estudio }\end{array}$ & Primer año & Segundo año & Tercer año & Cuarto año \\
\hline $\begin{array}{l}1876 \text { (plan de } \\
\text { tres años) }\end{array}$ & Labores & Labores & $\begin{array}{l}\text { Economía } \\
\text { Doméstica e } \\
\text { Higiene } \\
\text { Doméstica }\end{array}$ & - \\
\hline $\begin{array}{l}1880 \text { (plan de } \\
\text { tres años) }\end{array}$ & - & Labores & $\begin{array}{l}\text { Economía } \\
\text { Doméstica }\end{array}$ & - \\
\hline $\begin{array}{l}1886 \text { (plan de } \\
\text { cuatro años) }\end{array}$ & Labores & Labores & $\begin{array}{l}\text { Economía } \\
\text { Doméstica }\end{array}$ & $\begin{array}{l}\text { Economía } \\
\text { Doméstica }\end{array}$ \\
\hline $\begin{array}{l}1887 \text { (plan de } \\
\text { tres años) }\end{array}$ & Labores & $\begin{array}{l}\text { Economía } \\
\text { Doméstica y }\end{array}$ & $\begin{array}{l}\text { Labores, corte } \\
\text { y confección }\end{array}$ & - \\
\hline $\begin{array}{l}1903 \text { (plan de } \\
\text { cuatro años) }\end{array}$ & $\begin{array}{l}\text { Economía } \\
\text { Doméstica }\end{array}$ & Igual & Igual & Igual \\
\hline $\begin{array}{l}1905 \text { (plan de } \\
\text { cuatro años) }\end{array}$ & $\begin{array}{l}\text { Labores y } \\
\text { Economía }\end{array}$ & Igual & Igual & Igual \\
\hline $\begin{array}{l}1914 \text { (plan de } \\
\text { cuatro años) }\end{array}$ & $\begin{array}{l}\text { Labores } \\
\text { Labonomía }\end{array}$ & Labores & Labores & Eoméstica \\
\hline
\end{tabular}

Fuente: elaboración propia en base a los planes y programas oficiales.

\section{LOS LIBROS DE TEXTOS: ENSEÑANZA PRÁCTICA Y EDUCACIÓN DE LAS EMOCIONES Y COMPORTAMIENTOS}

La mayoría de los libros que se utilizaban para dar ambas asignaturas se encontraban bajo el rótulo de Economía Doméstica y tenían en su interior, capítulos sobre Labores, es decir, costura, bordado y tejido. Asimismo, estos primeros manuales planteaban temas similares a las otras 
asignaturas que ya existían o que se fueron incorporando al currículum escolar: Trabajo Manual, Urbanidad, Moral, Puericultura, Higiene e Higiene Doméstica, entre otras.

Para poder conocer cuáles eran los libros recomendados por las autoridades, hemos consultado los listados de los inventarios o compras que habían hecho los funcionarios de la Dirección General de Escuelas de la provincia de Buenos Aires y del Consejo Nacional de Educación, y que salían publicados en las revistas oficiales. Mencionaremos a continuación, con el año de la primera edición entre paréntesis, los que tuvieron mayor circulación: Guía de la mujer en el siglo actual o Lecciones de Economía Doméstica para las madres de familia, escrito por la docente española Pilar Pascual de San Juan y editado por primera vez en 1865; Lecciones de Economía Doméstica (1887), de Cipriano Torrejón y Lucía Aïn de Torrejón; Economía e Higiene Doméstica (1888) editado en Estados Unidos por Appleton y escrito por Florencia Atkinson y Juan García Purón; Varios asuntos de Política doméstica y Educación (1890) del ex director -de origen español- de la Escuela Normal de Paraná, José M. Torres; Economía Doméstica al alcance de las niñas (1901) de la maestra Emilia Salzá; El Vademécum del hogar. Tratado práctico de Economía Doméstica y Labores (1903) de la maestra Aurora Stella del Castaño; y Consejos a mi hija. Lecturas de propaganda moral (1903), de Amelia Palma. ${ }^{16}$

Como hemos visto, Economía Doméstica era una asignatura que tenían los planes de estudio de las primarias y las Escuelas Normales. Había otros establecimientos nacionales, como los Liceos de Señoritas y algunas Escuelas Profesionales, donde esta materia se denominaba diferente: «Ciencias y Artes Domésticas». De acuerdo a la maestra y médica Cecilia Grierson, que daba clases en el Liceo de la ciudad de Buenos Aires, esto era así porque las «Ciencias Domésticas» resultaban una disciplina de mayor complejidad que la Economía Doméstica, ya que estaban fundadas en el «conocimiento científico».17 Grierson, en el Primer

\footnotetext{
16 Hemos elaborado un artículo -que actualmente está en revisión- donde desarrollamos con más detalle el contenido de todos estos manuales.

17 Grierson había sido enviada por el Ministerio en 1899 para estudiar la enseñanza de Economía Doméstica y Labores en las escuelas técnicas o industriales femeninas de Europa. En 1900 el Estado nacional creó la primera Escuela Profesional de Mujeres en la Capital y la propia Grierson fundó en 1902 una Escuela Técnica del Hogar. Cecilia Grierson, Educación Técnica de la mujer (Buenos Aires: Tipografía de la Penitenciaría Nacional, 1902).
} 
Congreso Femenino Internacional realizado en Buenos Aires en 1910, expresó que aún no se había podido avanzar en el estudio de las «Ciencias Domésticas» porque había una carencia de textos en el país, desconociendo la existencia y calidad de los manuales que estaban circulando. Solicitó que se reemplazaran en todas las escuelas primarias y Normales, la asignatura Ciencias Domésticas por la «antigua enseñanza empírica de la Economía Doméstica». Si bien su propuesta no tuvo éxito, comenzaron a circular otros libros, escritos especialmente para los Liceos. ${ }^{18}$

Retomando el análisis de los siete manuales que mencionamos antes, estos apuntaban, como dijimos, a formar a la futura ama de casa, es decir, tanto a que las niñas y jóvenes aprendieran los rudimentos de la contabilidad doméstica y la enseñanza práctica de las tareas del hogar, como a la educación de las emociones y comportamientos. Partían de la base que el ama de casa era la señora encargada del manejo de los fondos que ingresaran y solía ser la esposa del jefe de familia o su viuda y a veces, su hija mayor. Para ello, debía saber leer, escribir y las cuatro reglas de aritmética. Otro de los propósitos de esta materia, coincidían, era el de inspirar a las niñas el amor a la vida doméstica. El problema era, decían en su manual los esposos Torrejón, que «la mujer moderna» había olvidado que «el saber Matemáticas» no se oponía a que se entendiese cómo se limpiaba la casa y se hacían las compras, ni el conocer «arte poético» autorizaba a «no saber zurcir los calcetines y remendar un vestido». ${ }^{19}$ Y recordaba que estas eran tareas exclusivamente de las mujeres, ya que los hombres que las hacían debían ser considerados como «intrusos o maricas y nunca como varones». ${ }^{20}$ En el mismo tono, Atkinson y Purón elogiaban al Departamento de Instrucción Pública de Bélgica, que «muy acertadamente hizo reducir las asignaturas de Aritmética, Geografía, Historia, Geometría, Ciencias Naturales, Literatura, etc.» para que se pudiese dar Economía Doméstica en las escuelas públicas. ${ }^{21}$

\footnotetext{
18 Uno de estos manuales fue el publicado en 1914, Administración e Higiene del Hogar, escrito por el normalista Ángel C. Bassi, quien era profesor de Ciencias Domésticas del Liceo de Señoritas de La Plata. Dos reseñas de este libro están en Caldo, «Una disciplina con urbanidad» y Aguilar, El hogar como problema.

19 Cipriano Torrejón y Lucía Aïn de Torrejón. Lecciones de Economía Doméstica (Buenos Aires: Casa editorial, 1887): 8.

20 Torrejón y Torrejón, Lecciones de Economía Doméstica, 26.

21 Florencia Atkinson y Juan G. Purón. Economía e higiene doméstica arreglada para uso de la familia en general y para texto en escuelas y colegios de señoritas por la profesora (New York: Appleton, Sexta edición [1888] 1912): 4.
} 
Los/as autores/as de los manuales partían de la base que las madres transmitían un saber «rutinario y tradicional» sobre el hogar y no «con base científica», esto era, apoyado en los conocimientos de "la Higiene, la Química, la Fisiología y la Psicología» que solo la Economía Doméstica podía ofrecer. ${ }^{22}$ En los textos se enseñaba, además de administrar mensualmente los ingresos que aportaba el esposo; a hacer las compras gastando lo menos posible y adquiriendo alimentos de buena calidad que conservaran la salud de la familia; de qué forma hacer la limpieza y ventilación de la casa para que circulara mejor el aire; cuál era la manera más adecuada de lavar y planchar la ropa para combatir gérmenes, virus y bacterias; cómo elaborar diferentes prendas de vestir y/o remendarlas; de qué manera preparar remedios caseros y curar a los/as accidentados/as; y, en menor medida, cómo cuidar y educar a los/as hijos/as. ${ }^{23}$

Los/as autores/as decían dirigirse a las futuras amas de casa ricas y pobres, por ello, las estudiantes tenían que saber cómo se hacían las cosas, para hacerlas ellas mismas o mandarlas a hacer a los sirvientes. Cuando se hablaba de la limpieza del hogar, los/as autores/as se referían siempre a una casa (podía ser alquilada) y nunca a una pieza de conventillo. Una familia pudiente o humilde, explicaban, para mantener las mínimas condiciones de higiene y moral, debía vivir en una casa luminosa y aireada con cocina, dos dormitorios, comedor y un jardín. El libro de Atkinson y Purón presentaba el ejemplo del hogar más grande y mejor equipado de todos, donde se instruía desde cómo limpiar muebles de todo tipo, bibliotecas y repisas con adornos, hasta alfombras, tapices, cortinas, cuadros, lámparas, cubiertos de plata y manteles, entre otros.

De todos los manuales, el que seguía más ajustadamente los contenidos de la primaria y de las Normales, era el de la maestra Castaño, cuyo texto tenía casi 500 páginas y 400 grabados, y estaba dividido en tres partes: la primera era sobre la casa y las enfermedades más comunes; la segunda se refería a la costura, el bordado y el tejido; y la tercera parte tenía numerosas y variadas recetas. Además, era el único que

\footnotetext{
22 Amelia Palma. «La educación de la mujer», El Hogar y la escuela. Revista Ilustrada de Educación, n. ${ }^{\circ} 114$ (1899): 1436.

23 Este último contenido sobre el cuidado de los/as hijos/as no se encontraba, en general, muy desarrollado en los textos, dado que, como vimos, no siempre estuvo en los programas de la materia. Con el tiempo se introdujo una asignatura más específica para las alumnas, Puericultura, con sus consiguientes manuales.
} 
incorporaba los programas de Trabajo Manual. Otro que tenía recetas era el de la española San Juan, y el de los Torrejón contaba con algunas y mostraba también cómo criar animales domésticos.

En relación con la educación de las emociones y la adquisición de comportamientos adecuados, los textos tenían en común que reproducían una mirada tradicional y jerárquica de la familia y asumían como natural la subordinación de la mujer. A lo largo de los capítulos, los/as autores/as advertían, de manera más o menos explícita, que resultaba necesario que las estudiantes adquiriesen la capacidad de dominar las emociones negativas del carácter (malhumor, orgullo, vanidad, egoísmo, ira) y respecto a las tareas domésticas (asco, rechazo). En su futura vida como amas de casa, sugerían, lo ideal era que se mostrasen siempre obedientes, generosas, humildes, discretas, sumisas y componedoras. La única manera de obtener la felicidad plena, le explicaban a las estudiantes, era que la dueña de casa, cualquiera fuese su clase social, tuviese buen genio y aprendiese los principios de la Economía Doméstica. Estos implicaban que fuese capaz de hacer grandes sacrificios personales en aras de vivir sin sobresaltos y, si sucedía alguna desgracia, supiese cómo salvar al hogar de la miseria. A través de esta asignatura, se esperaba que la esposa aprendiese a llevar la contabilidad del hogar con el salario que su marido le entregaba todos los meses, cuidando que los ingresos no fuesen más altos que los egresos, llevando una libreta para anotar todos los movimientos diarios de dinero y tratando siempre de ahorrar. Este correcto manejo del dinero del esposo, incluía un monto para los gastos personales de él, el pago a tiempo a los sirvientes (cuando los había) y la limosna a los pobres. En el libro de San Juan, se incluían historias de familias proletarias y distinguidas que habían logrado salir adelante gracias a la buena administración de la madre, una viuda o la hija mayor.

Una de las peores cualidades de la mujer, se decía, era ser holgazana y en el libro de la maestra Salzá, se enseñaba cómo debía distribuirse el tiempo diario, se tuviese o no ayuda de los sirvientes: levantarse temprano, hacer limpieza y ventilación de la casa; preparación y toma del desayuno; compra diaria de comestibles y su inspección; preparación y toma del almuerzo; descanso; quehaceres de composturas y remiendos; atenciones domésticas y sociales; preparación y toma de la cena; descanso, lecturas y conversaciones útiles y recreativas; arreglo de cuentas de los 
gastos hechos durante el día; y revisión de las habitaciones y reposo. Respecto a las faenas semanales de la casa, los lunes recomendaba mojar y jabonar la ropa sucia; los martes ponerles lejía y enjuagarlas; los miércoles repasarlas por última vez, hacer compras de telas y demás compras; los jueves remendar y zurcir la ropa limpia; los viernes plancharla; los sábados limpiar la casa; y los domingos cumplir con los deberes religiosos, y hacer paseos y distracciones. Una de las misiones más importantes de la madre, añadían, era enseñarles a sus hijas desde pequeñas cómo podían colaborar con estas obligaciones.

El texto del maestro Torres tenía lecturas ejemplares sobre las consecuencias de ser perezosa, envidiosa, dominante, iracunda y opulenta, entre otros defectos típicamente femeninos, según indicaba. ${ }^{24} \mathrm{La}$ joven perezosa, argumentaba, no hacía ningún esfuerzo mental para estudiar, pero se levantaba enseguida cuando una amiga la invitaba a un paseo campestre. Si continuaba así, esta mujer se convertía en una «inútil, incapaz y culpable de su incapacidad». Sobre la envidia aseguraba que las mujeres eran más propensas que los hombres a ese sentimiento y esto las hacía «tétricas». Asimismo, la mujer que era dominante debía evitar ese impulso y «consagrarse a dulcificar los sufrimientos de la existencia y a suplir bondadosamente toda falta de inteligencia o de voluntad» que viese en su marido y sus hijos. Este "despotismo femenino», que era la pretensión de imponer su personal manera de sentir, debía ser reprimida para no convertir «la vida doméstica» en un "verdadero infierno». La mujer iracunda era la de mal genio, y «labraba su desgracia y la de su familia» siendo de esa manera. La mujer opulenta, tenía «falseado el espíritu y alterada la razón por el orgullo y la vanidad», caminaba siempre «hacia la perdición por querer lucir sus brillantes atavíos» y con ello iba «derecho al abismo» y la miseria. Esta última cuestión se encontraba en casi todos los demás libros, donde se remarcaba que la mujer, por sobre todas las cosas, debía evitar realizar gastos para sí misma (en vestidos, joyas o accesorios) sin consultar al esposo, porque esa era una de las causas seguras de la ruina económica y la infelicidad del hogar.

24 El párrafo que sigue está basado en el texto de José María Torres. Varios asuntos de Política Doméstica y Educación (Buenos Aires: Estrada, 1890). 


\section{ALGUNOS INFORMES Y TESTIMONIOS ACERCA DE CÓMO ERA Y CÓMO DEBÍA SER, LA ENSEÑANZA DE ECONOMÍA DOMÉSTICA Y LABORES EN LA ESCUELA PRIMARIA}

Acerca de cómo se enseñaban estas dos materias, contamos con algunos testimonios e informes de lo que sucedía en las aulas de primaria, que nos devuelven una idea aproximada sobre esta cuestión, siempre difícil de conocer acabadamente. En base a estas impresiones, creemos que estos libros de Economía Doméstica los poseían solo las maestras -adquiridos en sus épocas de estudiantes de la Normal- quienes los usaban de guías para dictar sus clases.

Presentaremos primero un registro anterior al del período estudiado aquí, porque la cuestión que se planteaba alrededor de Labores, siguió vigente en la etapa posterior. En 1860, un alto funcionario de la provincia de Buenos Aires, opinaba que las actividades de Labores que se enseñaban en las escuelas de niñas no cumplían con objetivos educativos, ya que se las obligaba a elaborar «bordados de lujo» que les insumían «un tiempo infinito confeccionarlos» para vendérselos a las «clases acomodadas», cuando en realidad ese tiempo debían destinarlo a su instrucción o a trabajos manuales más útiles para el hogar. ${ }^{25}$ Efectivamente, la Sociedad de Beneficencia organizaba a fin de año una exhibición y venta de los mejores trabajos que elaboraban sus alumnas y lo recaudado contribuía en parte a su financiamiento. Unas décadas después, Cecilia Grierson mencionaba que, si bien la enseñanza de costura, corte y confección en las escuelas estaba bien dada, restaba combatir «la tendencia al lujo»y aconsejaba suprimir por completo los bordados en seda y oro y en cambio, dedicar más tiempo al zurcido, remiendo y renovación de lo usado. ${ }^{26}$

Por otra parte, una maestra de un pueblo bonaerense, relataba cómo le daba Economía Doméstica a sus alumnas de primaria y explicaba que, por un lado, procuraba brindarles ejemplos prácticos sobre cómo debían ser la vestimenta, el calzado y el manejo de la economía hogareña y por el otro, les leía el texto Guía de la mujer de Pilar de San Juan para que las niñas supiesen sus deberes cuando fuesen dueñas de casa, esposas y madres. ${ }^{27}$

\footnotetext{
25 s/a. «Premios y exhibiciones industriales», Anales de la Educación Común (1860): 495.

26 Grierson, Educación Técnica de la mujer, 166.

27 Petrona Guruciaga de, «Economía Doméstica», Revista de Educación, n. 37 (1884): 66-67.
} 
Una de las primeras inspectoras técnicas de Economía Doméstica y Labores en las escuelas primarias de la Capital, Clotilde Guillén, publicó una serie de notas en la revista oficial de nación. En una de ellas, Guillén aseguraba que los programas de la escuela primaria para las niñas debían ser "diametralmente distintos» a los varones, ya que a las niñas había que instruirlas para la vida doméstica y social y su educación debía tener un "carácter práctico y utilitario». ${ }^{28}$ Años después, el Ministerio la envió a Europa, junto con otros docentes, para observar cómo se daba Educación Doméstica en esos países. En un informe que preparó sobre ese viaje, relataba que en sus orígenes, esa asignatura se pensó para las clases trabajadoras, debido a que las autoridades observaron que existía una gran cantidad de obreros que estaban mal alimentados y viviendo en casas poco higiénicas. ${ }^{29}$ Por ello, los máximos funcionarios decidieron que había que educar a las mujeres, futuras amas de casa, y enseñarles la mejor manera de organizar un hogar.

Acerca de su trabajo como inspectora, advertía negativamente lo que ocurría con la asignatura Labores en las primarias. Ella había visto que en las clases, las maestras no podían seguir el plan oficial porque las niñas llevaban a la escuela los trabajos de costura que necesitaban sus familias, por lo que debían multiplicar sus esfuerzos teniendo que enseñar 30, 40 o 50 trabajos diversos que no guardaban entre sí ninguna relación. La inspectora creía que aquello no podía seguir así y su aprendizaje debía adecuarse a lo prescripto en los programas. ${ }^{30}$

Respecto a la enseñanza de Economía Doméstica, creía que estaba completamente «desvirtuada» porque se la había reducido a la práctica de la cocina, ya que cuando les preguntaba a las directoras de las escuelas cómo se había desarrollado el programa, casi invariablemente le contestaban que no habían podido hacer nada porque no tenían cocina en la escuela. ${ }^{31}$ Las maestras, se quejaba, consideraban que Economía

\footnotetext{
28 Clotilde Guillén, «Calidad de la educación femenina», El Monitor, n. ${ }^{\circ} 383$ (1904): 107.

29 Clotilde Guillén, «La Educación Doméstica en las escuelas europeas», en Ministerio de Justicia e Instrucción Pública. Educación Común en la Capital, Provincias y Territorios Nacionales (Buenos Aires: Kraft, 1907).

30 Clotilde Guillén, «La enseñanza de la costura en las escuelas primarias elementales de Francia», El Monitor, n. ${ }^{\circ}$ 406, 1906.

31 Clotilde Guillén, "Algunas observaciones sobre el funcionamiento de las clases de cocina», El Monitor, n. ${ }^{\circ}$ 406, 1906.
} 
Doméstica y cocina eran términos iguales. El otro problema era que en las pocas escuelas donde se daban cursos de cocina, su enseñanza se limitaba a la preparación de un reducido número de comidas. En la mayoría de los casos, se escribía en el pizarrón las sustancias que entraban en la composición con sus pesos y precios; se daba una explicación de las distintas fases de la preparación; y las alumnas en grupo hacían el plato. La inspectora criticaba que estas clases eran muy resumidas, porque no se enseñaba sobre el valor nutritivo de cada elemento ni la higiene de la alimentación, el régimen, la ración normal y la limpieza. Volvía a recordar que en los países de Europa y Estados Unidos, la Educación Doméstica perseguía los fines de llevar a los hogares obreros un mejoramiento de la vida económica y enseñarles a mirar el hogar como un centro de salud, alegría y arte. Para cumplir estos objetivos, la teoría de la alimentación debía ocupar un lugar preponderante para promover el estado general de salud del pueblo trabajador. Esta era parte de la misión de la escuela, "desconocerla», aseguraba, era "no ser maestra», sino un mero «empleado a sueldo». ${ }^{32}$

Guillén continuaba hablando sobre estas clases y mencionaba que solo había quince escuelas en la Capital donde se enseñaba cocina y en los quintos y sextos grados, aunque por fortuna, destacaba, el Estado había dispuesto una subvención para los gastos de esas clases. ${ }^{33}$ Esperaba que las autoridades instalaran muchas cocinas más y para los grados inferiores. Luego presentaba un plan que ella había elaborado para las escuelas, donde desarrollaba una clase práctica de «instrucciones para las clases de cocina». Proponía que las niñas se agruparan de a seis, simulando ser una «familia» a la que había que asignar diferentes tareas: preparar el fuego y llevar la contabilidad; lavar, cortar y preparar los alimentos; lavar, repasar los utensilios necesarios y procurar mantener el orden; cuidar la comida mientras estaba en el fuego; tender la mesa, lavar y planchar los repasadores y mantelería; y servir en la mesa y hacer la limpieza general. En las siguientes clases las alumnas se iban rotando. En cada lección debían invertirse alrededor de 2,50 \$ en la adquisición de los alimentos y la comida preparada debía ser aprovechada por los/as niños/as pobres de los grados infantiles. Posteriormente, la inspectora

\footnotetext{
32 Guillén, "Algunas observaciones sobre el funcionamiento de las clases de cocina», 185.

33 Clotilde Guillén, «Enseñanza de la cocina en la escuela primaria», El Monitor, no, 424, 1908.
} 
desarrollaba un plan teórico para el quinto y sexto grado con nociones sobre alimentos y bebidas. Esta propuesta, aclaraba, seguía el método grupal de enseñanza que se utilizaba en países como Suecia, Noruega, Dinamarca, Alemania y Bélgica. ${ }^{34}$ Unos años después, otra inspectora de Economía Doméstica de Capital confirmaba los dichos de Guillén, advirtiendo que las clases de Economía Doméstica solo se habían dado en aquellas escuelas que contaban con cocinas. En estas, las niñas habían preparado distintos platos, que luego servían a las alumnas pobres y de nutrición deficiente de los grados inferiores. ${ }^{35}$ En la década de 1920 otra inspectora explicaba que Economía Doméstica se daba en los quintos y sextos grados, y que las clases eran dictadas por las mismas maestras de grado, una vez por semana. Seguía habiendo un poco más de diez cocinas instaladas y pedía que se multiplicaran en todas las escuelas, pero cuando la escuela no tenía cocina, indicaba, se desarrollaba el siguiente programa: administración del hogar, inversión del dinero, quehaceres domésticos, higiene alimenticia y medicina casera, todas «nociones indispensables a la mujer» que aspirara a «manejar bien su casa». ${ }^{36}$

Por fuera de la ciudad de Buenos Aires, una maestra de Corrientes mencionaba que en Economía Doméstica las alumnas habían aprendido a elaborar distintas comidas, más de cuarenta preparaciones de tipo medicinal y habían practicado el lavado y planchado. ${ }^{37}$ En Labores, las niñas habían aprendido desde el zurcido hasta la confección de vestidos de 15 años, desde la simple letra de bordado hasta los lujosos bordados en seda, así como hacer toda clase de tejidos. A fin de año, se habían exhibido y puesto a la venta los mejores trabajos. En una Escuela Normal del interior de la provincia, su director Víctor Mercante informaba, en un tono positivo, que en la clase de Economía Doméstica, las niñas habían elaborado varios platos y confeccionado distintos presupuestos para calcular los costos. Los productos elaborados en las clases de Labores, seguía, los habían puesto a la venta a fin de año y la escuela había podido recolectar unos 2590 pesos, sobre todo con la confección de ropas que

\footnotetext{
34 Clotilde Guillén, «Instalación de una cocina escolar», El Monitor, n. 426, 1908.

35 Ministerio de Justicia e Instrucción Pública. Educación Común en la Capital, Provincias y Territorios Nacionales (Buenos Aires: Kraft, 1914).

36 Ministerio de Justicia e Instrucción Pública. Educación Común en la Capital, Provincias y Territorios Nacionales (Buenos Aires: Kraft, 1925): 59.

37 s/a, «Una escuela que produce», La Educación, n. . 272, 273/274 (1898).
} 
habían hecho las estudiantes de quinto y sexto grado. ${ }^{38}$ En una Escuela Normal de Salta, la directora contaba que en Labores de la escuela primaria, siguiendo las recomendaciones oficiales, se había abandonado la "exhibición de hermosos bordados en seda y oro», y de "vistosas telas con extraordinarios adornos», para otorgarle un sentido más educativo a esas clases: ahora se les enseñaba a las niñas a «confeccionar con corrección y brevedad un traje», a hacer un vestido, un zurcido, un remiendo y tejidos sencillos. ${ }^{39}$

\section{REFLEXIONES FINALES}

En este artículo analizamos qué lugar tuvieron en los planes de estudio las materias de Labores y Economía Doméstica, en qué se distinguían ambas asignaturas, de qué trataban los manuales de Economía Doméstica y de qué manera se impartían en las aulas de primaria. Respecto a la primera cuestión, hemos visto que en los planes de estudio de la provincia de Buenos Aires, la ciudad de Buenos Aires y de los cursos de magisterio, estas asignaturas tuvieron distintos desarrollos, aunque en estos tres ámbitos, en los planes de estudio para las niñas se eliminaron o les restaron minutos a otras asignaturas como Aritmética, Ciencias Naturales, Álgebra, Química y Física, para que ellas pudieran cursar en ese horario Labores y Economía Doméstica. En la provincia de Buenos Aires, desde 1876, Labores se dio casi siempre en los seis grados de la primaria y Economía Doméstica, de cuarto grado en adelante, y a partir de 1904, cuando se acortó la obligatoriedad de la primaria, se dejó solo Labores y se suprimió esta última asignatura. En la ciudad de Buenos Aires, las niñas también tuvieron menos carga horaria de las otras materias, asimetría que se corrigió hacia principios del siglo XX. Durante un breve lapso, Labores y Economía Doméstica se dieron de primero a sexto grado, pero luego, a la segunda se la fue dejando solo en los quinto y sexto grados. En el magisterio se repitió la misma desigualdad horaria hasta 1903, que los planes se igualaron y solo quedaron diferenciadas por sexo las materias prácticas: mientras ellas hacían Labores y Economía Doméstica, ellos cursaban Trabajo Manual. En el plan de 1914, Economía Doméstica quedó relegada al último curso.

\footnotetext{
38 Víctor Mercante, «La Escuela Normal de Mercedes», La Educación, n. ${ }^{\circ}$ 272, 273/274 (1898): 347.

39 s/a, «Escuela Normal de Niñas de Salta» La Educación, n. . 272, 273/274 (1898): 348.
} 
En relación con su contenido, en todas estas escuelas, Labores se pensó inicialmente como una materia para aprender la costura, el tejido y el bordado a mano, a la que luego se incorporó el manejo de la máquina de coser, aunque no todas las escuelas contaron con una. En general, los programas fueron similares en los tres establecimientos mencionados, es decir, existía un consenso acerca de qué debía impartirse y se buscó casi siempre que las niñas de todas las edades la recibieran. De acuerdo a los funcionarios, Labores debía ser para que las niñas aprendieran el manejo de la aguja para cuando fuesen amas de casa o bien por si abandonaban la escuela y tuviesen que trabajar en el oficio. Economía Doméstica, en cambio, se suponía que era una asignatura práctica pero también teórica, que tuvo distintos contenidos en los inicios, hasta que se estabilizaron. Fue además, una materia destinada casi siempre a las niñas más grandes, algunas de ellas próximas a casarse o a seguir el curso de magisterio. Estas jóvenes que podían terminar la primaria y continuar estudiando, pertenecían mayoritariamente a sectores bajos con aspiraciones o medios y medios altos, cuyas familias no necesitaban del salario de las menores. En síntesis, si Labores estaba pensada como una materia útil para las niñas de todas las edades y clases sociales, Economía Doméstica iba dirigida a las de más edad y pertenecientes a familias con cierto bienestar.

En tercer término, vimos cómo los libros de texto de Economía Doméstica-que incluían lecciones de Labores en su interior- se ocupaban, por un lado, de la contabilidad doméstica y la enseñanza práctica de las tareas del hogar siguiendo la «base científica» que brindaban la Higiene, la Química, la Fisiología y la Psicología, entre otras. Estas tareas se dividían en seis grupos vinculados a la limpieza del hogar; la cocina y las propiedades de los alimentos; el cuidado de los enfermos y la preparación de remedios caseros; la costura, tejido y bordado; el lavado y el planchado; y la crianza de los/as niños/as. Por otro lado, los manuales apuntaban a la educación de las emociones y la adquisición de los comportamientos adecuados, esto era, cómo debían controlar los sentimientos negativos, asumir como natural la subordinación, aprender a disfrutar de las actividades domésticas, la administración de la casa y el cuidado de la familia. Hemos mencionado que estos libros eran usados mayoritariamente por las maestras para dar clases y eran adquiridos individualmente por las estudiantes de magisterio. Para ellas, estas materias 
eran tanto para prepararlas para ser un ama de casa, como para que pudiesen dar clases si no había una docente específica en la escuela donde trabajaban.

Por último, presentamos algunos informes y testimonios sobre la enseñanza de estas dos materias en las aulas de primaria. Acerca de Labores, las autoridades creían necesario erradicar los trabajos lujosos como el bordado en seda y oro y enseñar a las niñas a realizar costuras prácticas como el zurcido, el remiendo, y la confección de prendas útiles. De todos modos, inspectoras y maestras observaban que en las clases, o bien se seguían elaborando piezas lujosas con el objetivo de venderlas luego en exposiciones escolares para beneficio de la escuela; o bien las maestras debían ayudar a terminar los trabajos de costura que las niñas llevaban desde sus casas. Aún así y con estas dificultades, en líneas generales, los contenidos prescriptos en Labores se iban desarrollando tal y como estaban pautados. Al contrario, en Economía Doméstica, sucesivas inspectoras del área se quejaban porque las maestras habían asumido que esta materia se reducía a las clases de cocina. La realidad era que existían muy pocas instalaciones en las escuelas de la Capital, por lo que las inspectoras les ordenaban que diesen los otros contenidos, como administración del hogar, quehaceres domésticos y medicina casera. En suma, existía una distancia bastante grande entre los programas de Economía Doméstica y lo que se daba en las aulas de la escuela primaria y una brecha menor entre los contenidos de Labores y lo que efectivamente se impartía en las clases.

Para terminar, cabe recordar, como han señalado otros estudios, que estas nociones acerca del lugar de la mujer en la sociedad que reproducían las asignaturas de Economía Doméstica y Labores, estaban lejos de ser una excepción, y se encontraban en los contenidos y textos escolares de las demás materias, que siguieron replicándose casi del mismo modo en la escuela durante buena parte del siglo XX.

\section{Notas sobre la autora}

LaURa Graciela Rodríguez es profesora y licenciada en Historia, magíster en Ciencias Sociales y doctora en Antropología Social. Desde el año 2009 es investigadora del Consejo Nacional de Investigaciones Científicas 
y Tecnológicas (CONICET), con sede en el Instituto de Investigaciones en Humanidades y Ciencias Sociales (IdIHCS) de la Universidad Nacional de La Plata y profesora adjunta ordinaria del Departamento de Sociología de la misma universidad. Producto directo de sus pesquisas ha publicado más de 50 artículos con referato en el país y en el exterior. Es autora de los libros: Católicos, nacionalistas y políticas educativas en la última dictadura (1976-1983) (Rosario: Prohistoria, 2011); Civiles y militares en la última dictadura. Funcionarios y politicas educativas en la provincia de Buenos Aires (1976-1983), (Rosario: Prohistoria, 2012); y Universidad, peronismo y dictadura (1973-1983) (Buenos Aires: Prometeo, 2015). En coautoría con Flavia Fiorucci publicó el libro: Intelectuales de la educación y el Estado: maestros, médicos y arquitectos (Bernal, Universidad Nacional de Quilmes, 2018); y con Germán Soprano: Profesionales e intelectuales de Estado. Análisis de perfiles y trayectorias en la salud pública, la educación y las fuerzas armadas (Rosario, Prohistoria, 2018).

Actualmente está investigando la historia de las Escuelas Normales y de la formación de los/as maestros/as, y ha publicado recientemente los artículos -todos disponibles en línea- titulados: "Normalismo y mujeres. Las maestras en el Quién es Quién en La Plata (1972): trayectorias de una élite intelectual y profesional»; «Cien años de normalismo en Argentina (1870-1970). Apuntes sobre una burocracia destinada a la formación de docentes»; y "Los primeros Jardines de Infantes anexos a las Escuelas Normales (1884-1945). Debates alrededor de la infancia escolarizada».

\section{REFERENCIAS}

Aguilar, Paula. El hogar como problema y solución. Buenos Aires: Centro Cultural de la Cooperación, 2018.

Alloatti, Norma. «Desde la retórica doméstica a la inclusión de las hermanas de las letras en manuales escolares de fin de siglo XIX y comienzos del XX», ponencia presentada en XIII Jornadas Nacionales y VIII Congreso Iberoamericano de estudios de género: horizontes revolucionarios, voces y cuerpos en conflicto, http://eventosacademicos.filo.uba.ar/index.php/JNHM/XIII-VIII-2017/ paper/view/3585/2173. 
Armus, Diego. La ciudad impura. Buenos Aires: Edhasa, 2007.

Atkinson, Florencia y Purón, Juan G. Economía e higiene doméstica arreglada para uso de la familia en general y para texto en escuelas y colegios de señoritas por la profesora. New York: Appleton, Sexta edición [1888], 1912.

Caldo, Paula. «Una disciplina con urbanidad: la Economía Doméstica. Aproximaciones a la problemática desde El Monitor de la Educación Común». En Ahorran, acunan y martillan. Marcas de urbanidad en los escenarios educativos argentinos (primera mitad del siglo XX), compilado por Carolina Kaufmann, 175-206. Paraná: UNER, 2012.

Cammarota, Adrián. «Los consejos de Amalia a su hija Laura. Propaganda moral y construcciones genéricas en un texto escolar a comienzos del siglo XX en Argentina». De prácticas y discursos, n. ${ }^{\circ} 1$ (2012): 1-20.

Castaño, Aurora S. del. El Vademécum del hogar. Tratado práctico de Economía Doméstica y Labores. Buenos Aires: Juan Barra, 1903.

Grierson, Cecilia, Educación Técnica de la mujer. Buenos Aires: Tipografía de la Penitenciaría Nacional, 1902.

Liernur, Jorge F. «El nido de la tempestad. La formación de la casa moderna en la Argentina a través de manuales y artículos sobre economía doméstica (1870-1910)». Entrepasados, n. ${ }^{\circ} 13$ (1997): 7-36.

Lobato, Mirta. Historia de las trabajadoras en la Argentina (1869-1960). Buenos Aires: Edhasa, 2007.

Nari, Marcela. «La educación de la mujer (O acerca de cómo cocinar y cambiar pañales a su bebé de manera científica)». Revista Mora, n. ${ }^{\circ} 1$ (1995): 31-45.

Palma, Amelia. Consejos a mi hija. Lecturas de propaganda moral. Buenos Aires: Jacobo Peuser, 1903.

Rocchi, Fernando. "Concentración de capital, concentración de mujeres. Industria y trabajo femenino en Buenos Aires, 1890-1930». En Historia de las mujeres en la Argentina. Siglo XX, dirigido por Fernanda Gil Lozano, Valeria Pita y María G. Ini, 223-244. Buenos Aires: Taurus, 2000.

Rodríguez, Laura Graciela. "Maestros y maestras y la cuestión de género: planes de estudio, salarios y feminización (Argentina, 1870-1914)». Descentrada. Revista interdisciplinaria de feminismos y género, n. ${ }^{\circ} 1$ (2021): 1-17.

Salzá, Emilia. Economía Doméstica al alcance de las niñas. Buenos Aires: Cabaut [1901] 1925.

San Juan, Pilar Pascual de. Guía de la mujer en el siglo actual o Lecciones de Economía Doméstica para las madres de familia. Barcelona: Blas Camí (13 edición) [1865], 1909.

Torrejón, Cipriano y Torrejón, Lucía Aïn de. Lecciones de Economía Doméstica. Buenos Aires: Casa editorial, 1887.

Torres, José María. Varios asuntos de Política Doméstica y Educación, Buenos Aires: Estrada, 1890. 